\title{
A Linear Inverse Model of Tropical and South Pacific Seasonal Predictability
}

\author{
JIALE LOU \\ Institute for Marine and Antarctic Studies, University of Tasmania, and ARC Centre of Excellence for Climate System \\ Science, University of Tasmania, Hobart, Tasmania, Australia \\ TERENCE J. O'KANE \\ CSIRO Oceans and Atmosphere, Hobart, Tasmania, Australia
}

NeIL J. HolbROOK

Institute for Marine and Antarctic Studies, University of Tasmania, and ARC Centre of Excellence for Climate Extremes, University of Tasmania, Hobart, Tasmania, Australia

(Manuscript received 19 July 2019, in final form 26 February 2020)

\begin{abstract}
A multivariate linear inverse model (LIM) is developed to demonstrate the mechanisms and seasonal predictability of the dominant modes of variability from the tropical and South Pacific Oceans. We construct a LIM whose covariance matrix is a combination of principal components derived from tropical and extratropical sea surface temperature, and South Pacific Ocean vertically averaged temperature anomalies. Eigendecomposition of the linear deterministic system yields stationary and/or propagating eigenmodes, of which the least damped modes resemble El Niño-Southern Oscillation (ENSO) and the South Pacific decadal oscillation (SPDO). We show that although the oscillatory periods of ENSO and SPDO are distinct, they have very close damping time scales, indicating that the predictive skill of the surface ENSO and SPDO is comparable. The most damped noise modes occur in the midlatitude South Pacific Ocean, reflecting atmospheric eastward-propagating Rossby wave train variability. We argue that these ocean wave trains occur due to the high-frequency atmospheric variability of the Pacific-South American pattern imprinting onto the surface ocean. The ENSO spring predictability barrier is apparent in LIM predictions initialized in March-May (MAM) but displays a significant correlation skill of up to $\sim 3$ months. For the SPDO, the predictability barrier tends to appear in June-September (JAS), indicating remote but delayed influences from the tropics. We demonstrate that subsurface processes in the South Pacific Ocean are the main source of decadal variability and further that by characterizing the upper ocean temperature contribution in the LIM, the seasonal predictability of both ENSO and the SPDO variability is increased.
\end{abstract}

\section{Introduction}

The South Pacific decadal oscillation (SPDO; Chen and Wallace 2015; Lou et al. 2019) provides the Southern Hemisphere decadal contribution to the Pacific-wide interdecadal Pacific oscillation (IPO: Power et al. 1999; Folland et al. 2002), and is analogous to the Pacific decadal oscillation (PDO; Mantua et al. 1997) centered in the North Pacific. On interannual time scales, El NiñoSouthern Oscillation (ENSO) over the tropical Pacific is the most energetic mode of climate variability and has significant impact over the globe (McPhaden et al. 2006).

\footnotetext{
Corresponding author: Jiale Lou, jiale.lou@utas.edu.au
}

Further, various studies show that IPO-related variability, or more broadly Pacific decadal variability (PDV; e.g., Liu and Di Lorenzo 2018), resembles the ENSO pattern but with stronger extratropical signatures and meridionally broader tropical structures relative to ENSO (e.g., Zhang et al. 1997; Power and Colman 2006).

In the North Pacific, the PDO is now recognized to consist of multiple processes operating on different time scales (e.g., Schneider and Cornuelle 2005; Newman et al. 2016), which include atmospheric forcing (Hasselmann 1976; Di Lorenzo and Ohman 2013), oceanic dynamics (Deser et al. 2003; Capotondi et al. 2005; Schneider and Cornuelle 2005; Lyu et al. 2017), and ENSO teleconnections (Leathers et al. 1991; Newman et al. 2003; 
Zhang et al. 2018). However, the relative importance of each mechanism in determining the observed interdecadal variability is still an active area of research. In comparison to the PDO in the Northern Hemisphere (NH), Lou et al. (2019) show that in the Southern Hemisphere ( $\mathrm{SH})$ the atmospheric forcing and the oceanic subsurface processes combine to generate the observed SPDO variability in sea surface temperature (SST). While significant temporal correlations between ENSO and the SPDO have long been recognized, there has been relatively little focus on SPDO predictability. That said, Lou et al. (2019), using coupled AR1 linear stochastic models, most recently describe in detail the spatial distribution of South Pacific Ocean potential predictability. However, a more general model framework that describes how tropical and extratropical variability couple to produce the observed SPDO and its predictability has been lacking. Our study aims to address this gap by developing a reduced-order multivariate linear stochastic model capable of reproducing the observed decadal variability in the South Pacific and whose dynamics describe plausible mechanisms by which tropical ENSO and extratropical SPDO communicate on multiple time scales.

Hasselmann (1976) (see also Frankignoul and Hasselmann 1977) first introduced the linear stochastically forced model framework to investigate the lowfrequency variability of the upper ocean (i.e., SST) and in particular how atmospheric white noise forcing acts as the generator to trigger oceanic slow responses. For example, by using a first-order autoregressive (AR1) model, previous studies (e.g., Hasselmann 1976; Di Lorenzo and Ohman 2013) show that the Aleutian low (AL) is the key atmospheric driver of the PDO in the NH. Analogously, Lou et al. (2019) show that the atmospheric Pacific-South American pattern 1 (PSA1) and SPDO are more tightly related in the SH compared with the relationship between the AL and PDO, indicating that PSA1 is a critically important atmospheric driver of the oceanic responses associated with the SPDO.

To investigate relationships between the tropical and extratropical variability, Newman et al. (2003) extended the AR1 model by including the remote forcing of ENSO as a noise term and found the North Pacific Ocean not only acts to redden the atmospheric noise but also the ENSO signals from the tropics. Similarly, Power and Colman (2006) and Shakun and Shaman (2009) suggest that decadal variability in the South Pacific can be also regarded as a reddening of ENSO signals. These previous studies show that PDV in the extratropical Pacific in both hemispheres should be at least partly driven by tropical ENSO variability. That said, such models are limited by their simple assumptions. That is, PDV is remotely forced by ENSO without considering the extratropical forcing on the tropics. Therefore, to understand the dynamics and predictability of extratropical PDV, tropical variability must be included as part of the system, and not be considered as external to it.

Following Di Lorenzo and Ohman (2013), Lou et al. (2019) applied successive integrations of an AR1 model to investigate surface and subsurface temperature variability in the Pacific Ocean. Based on their analysis, Lou et al. (2019) conclude that the subsurface SPDO can be considered as the reddened response to the corresponding surface SPDO or cumulative integrated version of white-noise atmospheric variability from PSA1. Despite explaining a smaller fraction of the total variance, Lou et al. (2019) show that there is greater potential predictability of the subsurface SPDO relative to the subsurface PDO (their Fig. 11), indicating the importance of South Pacific subsurface processes as a key source of decadal variability and predictability beyond seasonal scales. Although previous studies suggest that interior oceanic mechanisms in the North Pacific exhibit multiple time scale variability ranging from seasonal to decadal (e.g., Alexander and Deser 1995; Deser et al. 1996; Alexander et al. 2002, 2008; Newman et al. 2016), it remains unclear which oceanic mechanisms drive the different observed responses in the extratropical North and South Pacific, especially since the role of South Pacific Ocean variability has been less discussed.

Although useful conceptually, these different variants of univariate AR1 models are limited by their simplicity (Newman 2007). Alternatively, a multivariate analysis may be more preferable to provide a better understanding of the underlying dynamics. The linear inverse model (LIM; Penland and Sardeshmukh 1995, hereafter PS95) or principal oscillation pattern analysis (POP; Hasselmann 1988; Penland 1989; von Storch and Xu 1990; von Storch et al. 1995) can be viewed as the multivariate analog to the univariate AR1 approach proposed by Hasselmann (1976).

The LIM/POP approach has been used for diagnostics and prediction in studies of atmospheric variability (von Storch and Xu 1990; Xu 1992; Schnur et al. 1993; Cavanaugh et al. 2015), tropical ENSO variability (Penland and Magorian 1993; PS95; Tang 1995; Penland and Matrosova 2006; Gehne et al. 2014; Capotondi and Sardeshmukh 2015), Atlantic SST variability (Penland and Matrosova 1998; Vimont 2012; Zanna 2012; Huddart et al. 2016), North Pacific decadal variability (Alexander et al. 2008), and the tropical-North Pacific coupled system (Newman 2007). Many of these studies have shown that the LIM/POP analysis is capable of revealing the 
appropriate linearized dynamics and provides a model of comparable forecast skill, from subseasonal to (inter) decadal time scales, to global circulation models.

Due to the deterministic and prognostic natures of univariate and multivariate AR1 models, such reducedorder stochastic models provide empirical knowledge that may lead to a better understanding of the underlying dynamics and more skillful predictions, providing benchmarks for more complex numerical models (Newman 2013). However, even a cursory reading of the literature indicates that studies on South Pacific decadal variability are lacking, regardless of the role that the South Pacific might play as a potentially significant source of decadal variability and predictability.

This study uses a LIM/POP to diagnose the dynamics and predictability of South Pacific decadal variability, and highlights connections between tropical and extratropical and surface to subsurface temperature variations. This paper is organized as follows. The data used in this study and the LIM methodology are described in section 2. In section 3, the LIM is developed and the dynamics of South Pacific decadal variability, including the connections between the tropical Pacific and South Pacific and the relationships between the surface and subsurface variability, are analyzed. Predictability based on the developed LIM is also investigated in section 3. Section 4 provides the discussion and conclusions.

\section{Data and methods}

\section{a. Data and ocean general circulation model}

The observed and simulated datasets used in this study are the same as used in Lou et al. (2019). The model used was an atmosphere-forced ocean general circulation model, the Australian Community Climate Earth System Simulator-Ocean (ACCESS-O) configuration of the GFDL MOM4p1 ocean-ice code (Delworth et al. 2006). The detailed model configuration of this particular variant of ACCESS-O has been described by O'Kane et al. (2014b). ACCESS-O is forced by observed atmospheric fields from the Coordinated Ocean-Ice Reference Experiments (CORE; 1948-2007) (Griffies et al. 2009) and has 50 model levels in the vertical covering $0-6000 \mathrm{~m}$. For comparison, the original $360 \times$ 300 tripolar ACCESS-O ocean model grid has been interpolated to a regular $2.5^{\circ} \times 2.5^{\circ}$ grid in this study.

The observed monthly SST data are taken from the Hadley Sea Ice and Sea Surface Temperature analysis 1.1 (HadISST 1.1; Rayner et al. 2003) available at https:// www.metoffice.gov.uk/hadobs/hadisst/data/download.html. For the purposes of our analysis, the HadISST data have been regridded to a $2.5^{\circ} \times 2.5^{\circ}$ grid.
At the same time, the atmospheric PSA variability was constructed by using the monthly mean $500-\mathrm{hPa}$ geopotential height (Z500) reanalysis data in this study, taken from the National Centers for Environmental PredictionNational Center for Atmospheric Research (NCEP-NCAR) reanalysis and available at https://www.esrl.noaa.gov/ $\mathrm{psd} /$ data/gridded/data.ncep.reanalysis.pressure.html. The $Z 500$ data were analyzed on the $2.5^{\circ} \times 2.5^{\circ}$ grid. To match the period of CORE forcing of the simulated data, all the observed and reanalysis data used in this study have been truncated to the period of 1948-2007.

In performing the empirical orthogonal function (EOF) analysis, we made use of the detrended anomalous monthly data. The seasonal climatology (calculated using the entire length of the record from 1948 to 2007) was removed from the monthly data at each grid point to derive the anomalies. Then, the linear trend was removed. The principal component (PC) time series derived from the EOF analysis is regarded as the climate index.

Following the approach by Davis (1976), significance tests of the correlation coefficients have been performed. This approach takes account of the effective number of degrees of freedom due to serial correlation, and then a simple $t$ statistic was applied to assess whether the respective time series were significantly correlated.

\section{b. Linear inverse model}

Linear inverse modeling assumes that the relevant dynamics can be written in the form of a linear stochastic differential equation:

$$
\frac{d \mathbf{x}}{d t}=\mathbf{L x}+\boldsymbol{\xi},
$$

where the state vector $\mathbf{x}$ can be expressed as the sum of the linear deterministic dynamics and a stochastic forcing term $\boldsymbol{\xi}$ (i.e., rapidly decorrelating white noise). In high-dimensional datasets, some form of dimension reduction is typically applied to determine $\mathbf{x}$. In this study, we make two choices for the model state vector $\mathbf{x}$,

$$
\mathbf{x}=\left[\begin{array}{l}
\mathrm{SST}_{\mathrm{TP}} \\
\mathrm{SST}_{\mathrm{SP}}
\end{array}\right]
$$

or

$$
\mathbf{x}=\left[\begin{array}{c}
\mathrm{SST}_{\mathrm{TP}} \\
\mathrm{SST}_{\mathrm{SP}} \\
\mathrm{VAT}_{\mathrm{SP}}
\end{array}\right],
$$

where in Exp1 we considered a combination of both the tropical Pacific SST (i.e., $\mathrm{SST}_{\mathrm{TP}}$ within $20^{\circ} \mathrm{S}-20^{\circ} \mathrm{N}$, $120^{\circ} \mathrm{E}-60^{\circ} \mathrm{W}$ ) and the South Pacific SST (i.e., $\mathrm{SST}_{\mathrm{SP}}$ in the region $70^{\circ}-22.5^{\circ} \mathrm{S}, 120^{\circ} \mathrm{E}-60^{\circ} \mathrm{W}$ ), whereas in Exp2 
we introduced additional subsurface variability in the form of the vertically averaged temperature (VAT) from 5 to $280 \mathrm{~m}$ in the South Pacific $\left(\mathrm{VAT}_{\mathrm{SP}} ; 70^{\circ}-22.5^{\circ} \mathrm{S}\right.$, $\left.120^{\circ} \mathrm{E}-60^{\circ} \mathrm{W}\right)$. Due to the paucity of subsurface observations over the decades prior to Argo, we have had to rely on the simulated VAT from 5- to 280-m depth, a range of vertical scales encompassing variability within the mixed layer and thermocline for most tropical and subtropical regions.

The matrix $\mathbf{L}$ in Eq. (1) represents the time-independent dynamical operator defining the evolution of $\mathbf{x}$. For a system with stationary statistics, it can be shown that $\mathbf{L}$ is dissipative (i.e., the real parts of the eigenvalues of $\mathbf{L}$ are negative). The matrix $\mathbf{L}$ is given by

$$
\mathbf{L}=\tau^{-1} \ln \left[\mathbf{C}\left(\tau_{0}\right) \mathbf{C}(0)^{-1}\right],
$$

where $\mathbf{C}\left(\tau_{0}\right)$ and $\mathbf{C}(0)$ are the time-lagged and zerolagged (cross-)covariance matrices of the state vector $\mathbf{x}$, respectively-that is, $\mathbf{C}\left(\tau_{0}\right)=\left\langle\mathbf{x}_{t+\tau_{0}} \mathbf{x}_{t}^{\mathrm{T}}\right\rangle$ and $\mathbf{C}(0)=\left\langle\mathbf{x}_{t} \mathbf{x}_{t}^{\mathrm{T}}\right\rangle$. The angle brackets here denote equivalently either an ensemble average or a time average over all $t$ for variables with stationary statistics). The dynamical operator $\mathbf{L}$ and the covariances can be determined from observational estimates at some lag $\tau_{0}$. In this study, we used $\tau_{0}=1$ month to ensure stability.

\section{Results}

\section{a. Preparation of the linear inverse model}

To reduce the number of spatial degrees of freedom, EOF analysis has been applied to the monthly TP SST, SP SST, and SP VAT respectively. To validate the reliability of the ACCESS-O simulations, we first calculated the leading EOFs/PCs of both HadISST and ACCESS-O SST. The respective leading PCs were then used to construct LIM experiments for the observed (Exp1a) and simulated (Exp1b) SST datasets. Figure 1 shows the leading two EOF patterns from both the observations and the simulation. The simulated SST patterns (Fig. 1) closely resemble the observed SST patterns, as do their relative explained variances-indicating that the model can adequately capture the spatial features of those modes. The VAT modes and indices have been constructed using the same regions defined for the SSTbased variability. The leading SST modes in the tropical Pacific and South Pacific (Fig. 1) clearly show ENSO and SPDO patterns. The second SST mode in the South Pacific (Figs. 1f,h) resembles a wave train pattern across the Pacific basin (see, e.g., Fig. 2 in Saurral et al. 2017). The leading VAT mode in the South Pacific (Fig. 1i) resembles its SST counterpart (Fig. 1g), which is referred to as the subsurface SPDO in Lou et al. (2019). By exploring the spatiotemporal features of the VAT SPDO, Lou et al. (2019) suggest that the VAT SPDO can be considered as the reddened response to the corresponding surface SPDO variability (i.e., Fig. 10 in Lou et al. 2019). The second VAT mode reflects the interior oceanic processes associated with ocean storm tracks in the subtropical South Pacific (see, e.g., Fig. 11 in O'Kane et al. 2014b).

The LIM was then constructed using the reduced space of EOFs, where the state vector $\mathbf{x}$ in the LIM is constructed on the basis of the corresponding PC time series. Here, we have retained the leading $10 \mathrm{EOFs} / \mathrm{PCs}$ to ensure that the dynamical operator $\mathbf{L}$ remains well defined with negative eigenvalues (i.e., it is invertible and dissipative). The leading four TP SST EOFs/PCs and six SP SST EOFs/PCs have been used in Exp1, and the leading two, six, and two EOFs/PCs for the TP SST, SP SST, and SP VAT, respectively, have been used in Exp2. The accumulated explained variances of the leading EOF modes have been listed in Table 1. The leading four SST EOFs in the tropical Pacific account for $73 \%$ and $70 \%$ of the total variance in the observations and simulation respectively, and the leading six SST EOFs in the South Pacific explain $61 \%$ and $54 \%$ of the corresponding variance in the observations and simulation. Also, $31 \%$ of the total variance has been explained by the first two SP VAT EOFs in the ACCESS-O model. In fact, the choices of using the leading 10 to $16 \mathrm{EOF} / \mathrm{PCs}$ in each LIM experiment to define the state vector and the different combinations of the leading PCs used from the different regions gave us similar results.

Before the LIM becomes useful, several validation tests needed to be performed. As described in the references therein, the tau test (see, e.g., PS95) was undertaken to ensure that the dynamical operator $\mathbf{L}$ is independent of the lag $\tau_{0}$ that is chosen to determine it. Figure 2 shows the dynamical operator $\mathbf{L}$ matrix for different time lags $\tau_{0}=1,2,3$, and 4 months respectively. We can see that the dynamical operator $\mathbf{L}$ under different time lags remains similar, indicating the stable properties of $\mathbf{L}$. However, this was not the case for larger lag times $>10$ months for which we exceed the Nyquist threshold (PS95; Newman 2007; Zanna 2012) due to the existence of some high-frequency variability (recall we did not filter the data). There are multiple reasons for which $\mathbf{L}$ might be substantially different from the different choices of time lags $\tau_{0}$, which include nonlinearity, instability, or nonstationarity of the true process being sampled (Penland 1989; von Storch et al. 1995). In this study, we used $\tau_{0}=1$ month in each experiment, thereby ensuring stability.

Once $\mathbf{L}$ was computed and the stability of $\mathbf{L}$ was tested, the statistics of the stochastic forcing $\boldsymbol{\xi}$ in Eq. (1) can be determined from the fluctuation-dissipation relation (PS95; Alexander et al. 2008) 

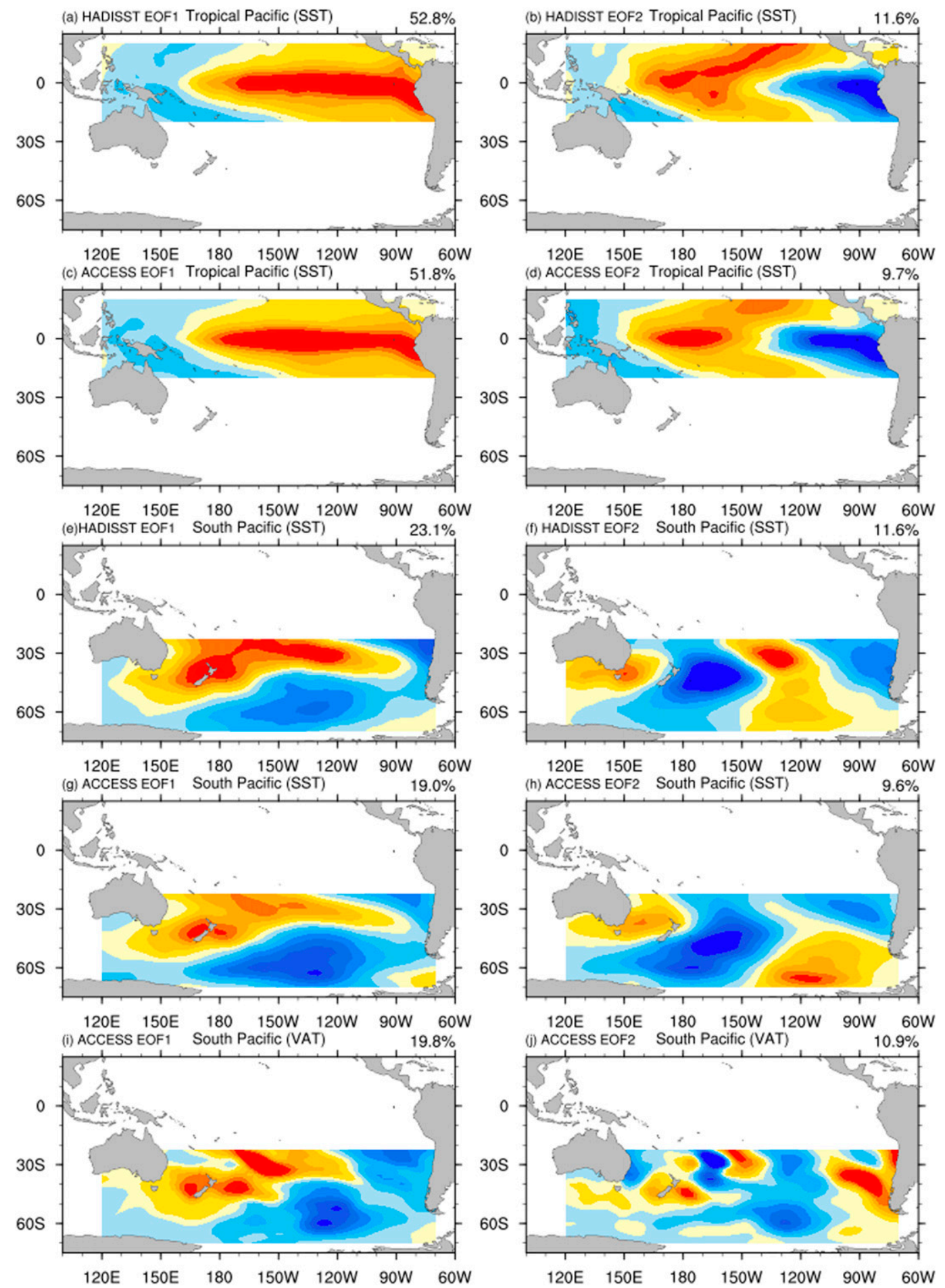

FIG. 1. The leading two EOF spatial patterns of the monthly SST anomalies in the (a)-(d) tropical Pacific and (e)-(h) South Pacific, and (i),(j) the leading two EOF spatial patterns of the monthly VAT anomalies in the South Pacific.

$$
\mathbf{L C}(0)+\mathbf{C}(0) \mathbf{L}^{\mathrm{T}}+\mathbf{Q}=0
$$

where $\mathbf{Q}=\left\langle\boldsymbol{\xi} \boldsymbol{\xi}^{\mathrm{T}}\right\rangle d t$ is the covariance matrix of the stochastic forcing multiplied by $d t$. To further validate that
Eq. (1) is an adequate model for the observed South Pacific SSTA, the noise covariance matrix $\mathbf{Q}$ should be positive definite (PS95). In our study, we found that all the eigenvalues of $\mathbf{Q}$ were positive in all the experiments 
TABLE 1. The accumulated explained variance for each of the LIM experiments.

\begin{tabular}{lccc}
\hline \hline & TP SST EOFs & SP SST EOFs & SP VAT EOFs \\
\hline Exp1a & $73 \%$ & $61 \%$ & - \\
Exp1b & $70 \%$ & $54 \%$ & - \\
Exp2 & $61 \%$ & $54 \%$ & $31 \%$ \\
\hline
\end{tabular}

indicating the South Pacific SST variability is, in general, linear with respect to constructing the LIM.

\section{b. Dynamics of combined TP SST and SP SST system}

The dynamics of the linear system can be diagnosed by applying eigen-decomposition to the operator $\mathbf{L}$. The eigenanalysis of the dynamical operator $\mathbf{L}$ has been referred to both as principal oscillation patterns (POPs; e.g., Hasselmann 1988; Penland 1989; von Storch et al. 1995; Tang 1995) or empirical normal modes (ENMs; PS95; Newman 2007; Alexander et al. 2008; Zanna 2012).

The ENMs or the POPs of a linear system, as given by Eq. (1) neglecting the forcing term $\boldsymbol{\xi}$, are the (left) eigenvectors $\mathbf{p}$ (also referred to as the eigenmodes in the references therein) of the dynamical operator $\mathbf{L}$ (i.e., $\mathbf{L} \mathbf{p}=\lambda \mathbf{p})$. As shown in Fig. 2, the $\mathbf{L}$ matrix is not symmetric and therefore some or all of its eigenvectors $\mathbf{p}$ and eigenvalues $\lambda$ are complex. However, since $\mathbf{L}$ is a real matrix, the conjugate complex eigenvalues $\lambda^{*}$ and eigenvectors $\mathbf{p}^{*}$ also satisfy the eigenequation $\mathbf{L}^{*}=\lambda^{*} \mathbf{p}^{*}$.
One of the advantages of the LIM is that we can estimate the damping time scales and the oscillatory periods of the various eigenmodes from the corresponding eigenvalues $\lambda=\sigma+i \omega$ directly, where $\sigma$ and $\omega$ are the real and imaginary parts of $\lambda$, respectively. Ordered by decreasing damping time scales, Table 2 shows the damping time scales $-1 / \sigma$ and the oscillatory periods $2 \pi / \omega$ of the ENMs of the 10-component dynamical system for Exp1a and b and Exp2 respectively.

In our study, the POP modes were derived from the sum of contributions of the weighted EOF modes, where the weight is the corresponding eigenvector. As the dynamical operator $\mathbf{L}$ is nonnormal with nonorthogonal eigenvectors (e.g., Penland and Matrosova 2006), the POP modes therefore might not be statistically independent. Figure 3 shows the leading three POP modes from Exp1a. The least damped stationary mode (Fig. 3a) is reminiscent of a SPDO pattern or "decadal ENSO" pattern with stronger extratropical signatures in the southwest Pacific and meridionally broader tropical structures on the interannual time scales relative to ENSO. This stationary mode has considerably longer damping time scales (10 months in Table 2) in Exp1a. The energetic phases (i.e., the real part of the eigenvectors) of POP2 and POP3 (Figs. 3b,c) combined are reminiscent of an interannual ENSO pattern with periods of $\sim 4$ years (Table 2 ). We can see that the interannual ENSO variability dominates the signal in the eastern tropical Pacific (Figs. 3b,c).
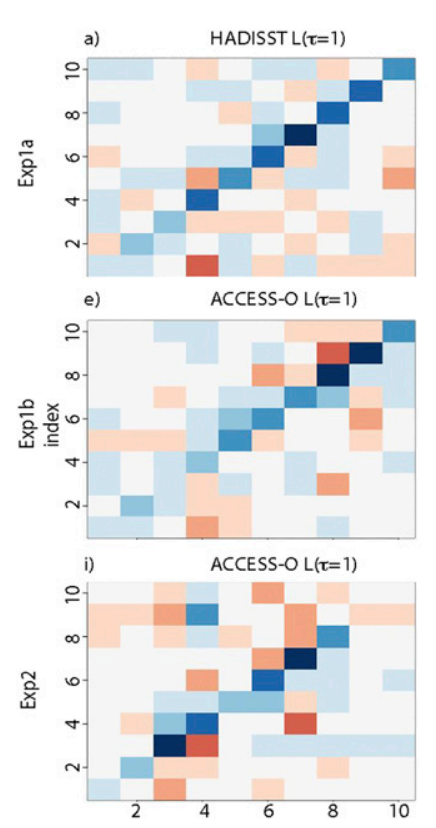
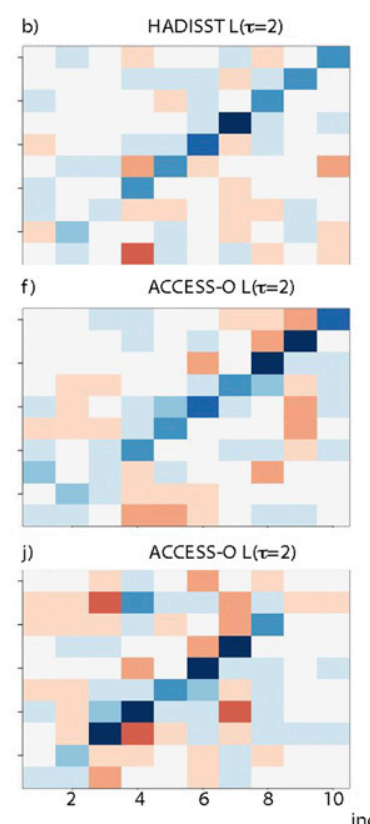
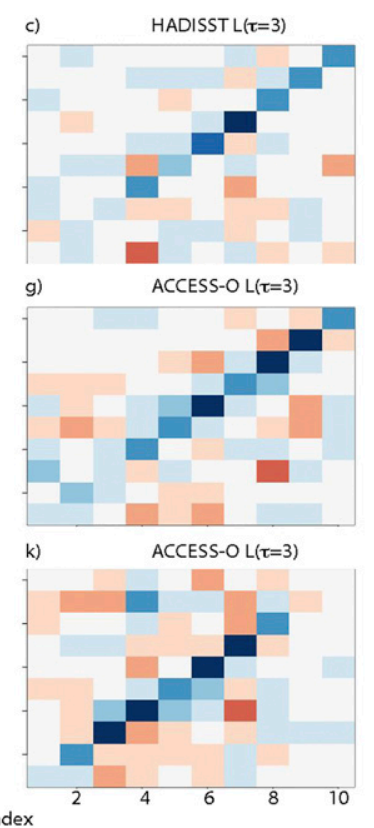
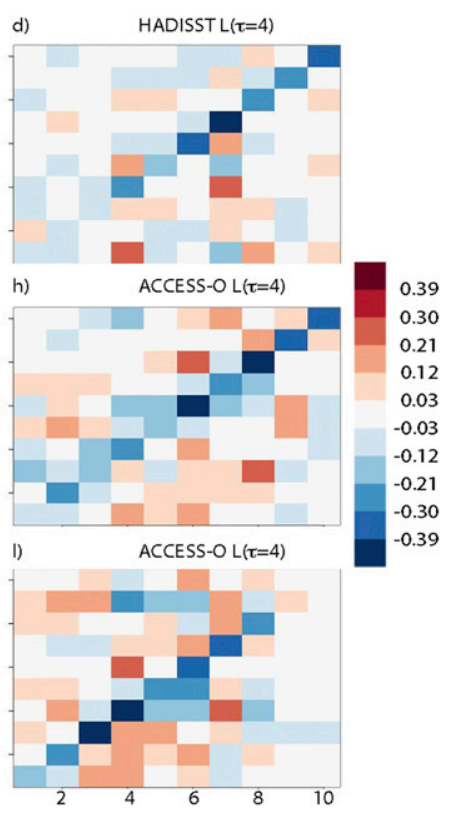

FIG. 2. The dynamical operator $\mathbf{L}$ matrix for different lags of $\tau_{0}=1,2,3$, and 4 months respectively in (top) Exp1a, (middle) Exp1b, and (bottom) Exp2. 
TABLE 2. Damping time scales and oscillatory periods of the eigenmodes of the coupled dynamical systems. Note that stationary modes have eigenvalues with zero imaginary parts (i.e., $\omega=0$ ) and propagating modes come in complex conjugate pairs.

\begin{tabular}{|c|c|c|c|}
\hline Dataset & Index & Damping time scale $(-1 / \sigma)$ (months) & Periods $(2 \pi / \omega)$ (months) \\
\hline \multirow[t]{7}{*}{ HadISST } & & Exp1 (TP SST + SP SST) & \\
\hline & 1 & 10.0 & - \\
\hline & 2 (two modes) & 8.5 & 49.2 \\
\hline & 3 (two modes) & 5.2 & 44.1 \\
\hline & 4 (two modes) & 4.0 & 130.3 \\
\hline & 5 & 3.5 & - \\
\hline & 6 (two modes) & 2.8 & 48.8 \\
\hline \multirow[t]{5}{*}{ ACCESS-O } & 1 (two modes) & 12.5 & 40.8 \\
\hline & 2 (two modes) & 10.3 & 232.6 \\
\hline & 3 (two modes) & 5.2 & 77.9 \\
\hline & 4 (two modes) & 3.6 & 47.0 \\
\hline & 5 (two modes) & 2.3 & 26.3 \\
\hline \multirow[t]{8}{*}{ ACCESS-O } & & Exp2 (TP SST + SP SST + SP V & \\
\hline & 1 & 101.9 & - \\
\hline & 2 (two modes) & 20.3 & 178.7 \\
\hline & 3 & 7.9 & - \\
\hline & 4 & 6.5 & - \\
\hline & 5 (two modes) & 3.5 & 53.0 \\
\hline & 6 & 2.9 & - \\
\hline & 7 (two modes) & 2.4 & 28.0 \\
\hline
\end{tabular}

The nonzero eigenvectors of $\mathbf{L}$ form a linear basis for the LIM. The state vector $\mathbf{x}$ can be expressed as the sum of contributions of these eigenvectors:

$$
\mathbf{x}=\sum_{j} z_{j}(t) \mathbf{p}_{j}
$$

Here, $z_{j}(t)$ is the projection time series for the $j$ th eigenvector, which is also called the POP coefficients or POP coefficient time series (e.g., Xu 1992; Tang 1995; von Storch et al. 1995). To get the POP coefficient time series, two approaches have been documented in the review paper of von Storch et al. (1995). That is, we can estimate the POP coefficients by either calculating the adjoint patterns (e.g., Penland 1989; Newman 2007) or by applying a least squares fit to the state vector $\mathbf{x}$ (e.g., von Storch et al. 1995). In our study, we adopted the former by calculating the adjoint patterns of $\mathbf{L}$ to estimate the corresponding POP coefficient time series. That is, the transpose of $\mathbf{L}$ has the same eigenvalues as $\mathbf{L}$, but different eigenvectors $\mathbf{q}$,

$$
\mathbf{L}^{\mathrm{T}} \mathbf{q}=\lambda \mathbf{q} .
$$

The matrices $\mathbf{p}$ and $\mathbf{q}$ form a biorthogonal set with $\mathbf{p}^{\mathrm{T}} \mathbf{q}=$ $\mathbf{p q}^{\mathrm{T}}=\mathbf{I}$ (I is the identity matrix). The POP coefficient time series can therefore be estimated from

$$
z_{j}(t)=\mathbf{q}_{j}^{\mathrm{T}} \mathbf{x}(t),
$$

where the $\mathbf{q}_{j}^{\mathrm{T}}$ is called the adjoint patterns of $\mathbf{L}$ (e.g., Newman 2007; Zanna 2012). Figure 3 (right) shows the leading three POP coefficient time series (only the time series associated with the most energetic phase of the complex eigenmodes are shown). We can see that the state vector used here has been split into different POP coefficient time series with distinct time scales. The least damped POP coefficient time series (Fig. 3d) is weakly correlated with the observed SP-PC1 (i.e., the SPDO time series) with a correlation of 0.42 ( $>95 \%$ significance). Both the POP2 and POP3 coefficient time series (Figs. 3e,f) are related to the observed TP-PC1 (i.e., ENSO) with correlations of -0.69 and 0.41 respectively, where all $r$ values are significant at the $95 \%$ level.

To compare with the observations, the same processes have been performed using Exp1b (ACCESS-O simulation). Figure 4 shows the most energetic phases of the leading two propagating POP modes in Exp1b and the corresponding time series. We can also see that the dynamics of the SST variability have been separated into at least two distinct time scales with one operating on interannual (Figs. 4a,c) and one on (inter)decadal (Figs. 4b,d). The mode associated with the interannual variability (Fig. 4a) dominates its signals narrowly in the equatorial Pacific and remains very similar to ENSO variability. The corresponding POP time series (Fig. 4c) is related to the simulated TP-PC1 (i.e., ENSO) with a correlation of 0.67 ( $>95 \%$ significance). The mode associated with the (inter)decadal variability (Fig. 4b) has a meridionally broader structure compared to its interannual counterpart. The corresponding time series (Fig. 4d) is consistent with the so-called climate regime shift in the mid-to-late 1970s and late 1990s (see, e.g., 

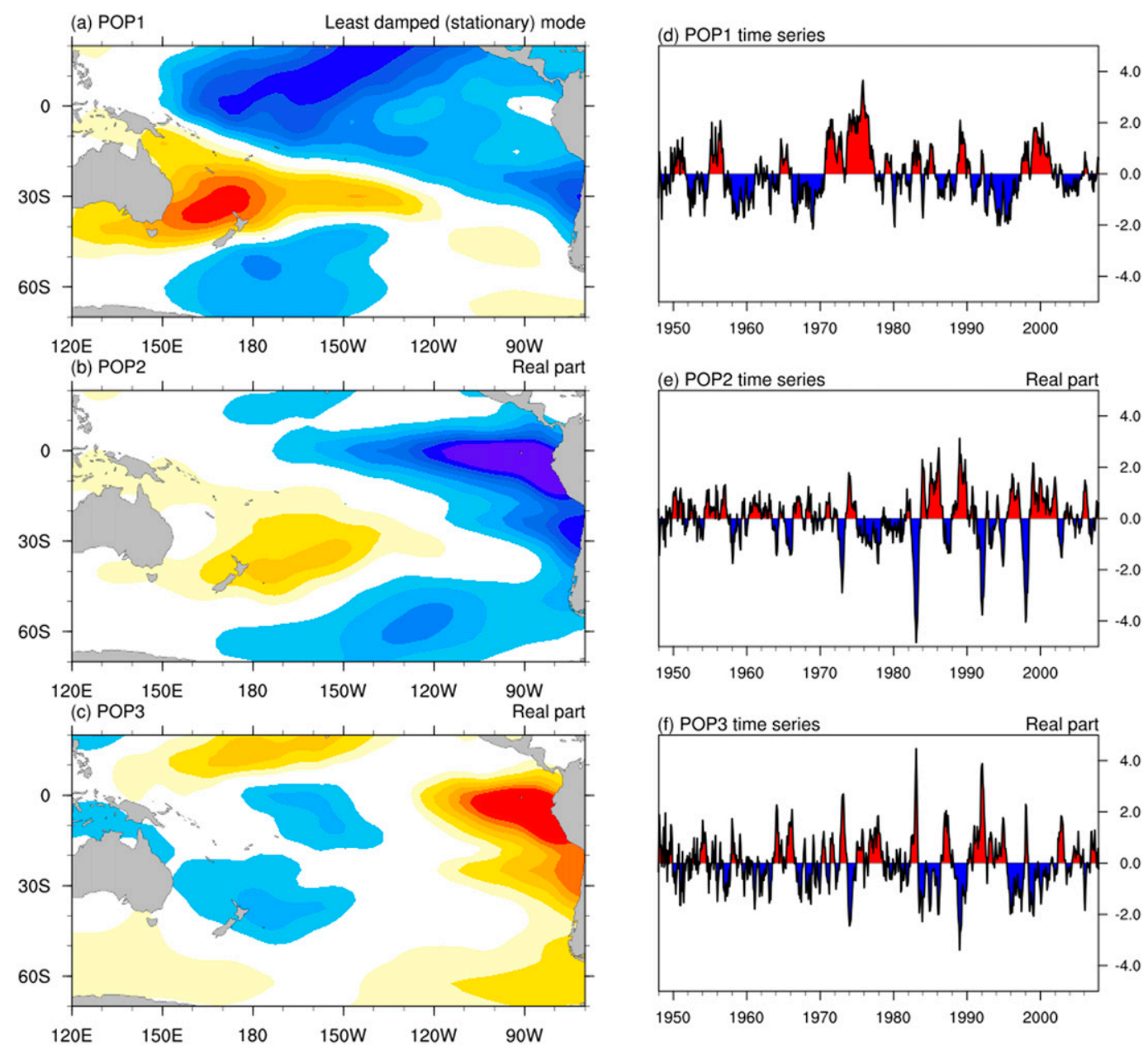

FIG. 3. The leading three least damped POP modes and the corresponding time series in Exp1a. The contour intervals are the same for all panels but are arbitrary. Red and blue shadings indicate opposite signs.

Fig. 2 in Lou et al. 2019), which is characterized as a conspicuously rapid transition between relatively stable atmospheric and oceanic states and a change of phase in the IPO during the middle to late 1970s (O'Kane et al. 2014a).

The summation in Eq. (4) can be decomposed into contributions from the relevant ENSO and SPDO modes (e.g., $A=\{1,2$ and 3$\}$ in Exp1a and $A=\{1$ and 2$\}$ in Exp1b, where $A$ refers to the least damped modes in each experiment), and a residual component. Therefore, Eq. (4) can be written as

$$
\mathbf{x}=\sum_{j \in A} z_{j}(t) \mathbf{p}_{j}+\underbrace{\sum_{j \notin A} z_{j}(t) \mathbf{p}_{j}}_{\text {residual }} .
$$

The interaction between the interannual ENSO mode and the (inter)decadal SPDO or ENSO-like mode plays a large part in giving rise to the overall SPDO variability, while the residual component is mainly associated with the higher-order noise modes. Reconstructions of the SPDO variability from the sum of just three (two) eigenmodes in the observations (simulation) are shown in Fig. 5. The correlations between the reconstructed SPDO and the observed or simulated SPDO are 0.81 and 0.73 , respectively (Fig. 5), indicating the SPDO represents not a single physical mode but rather a superposition of the interannual ENSO and (inter)decadal SPDO or ENSO-like decadal variability.

\section{c. Dynamics of combined TP SST, SP SST, and SP VAT system}

In experiment 1 , we only considered the surface temperature variability from both the tropical Pacific and South Pacific. We found that there were at least two distinct time scales operating, that is, interannual and (inter)decadal respectively, that contribute to the entire SPDO variability. However, where the decadal signals originate remains unclear. Many studies show that the 

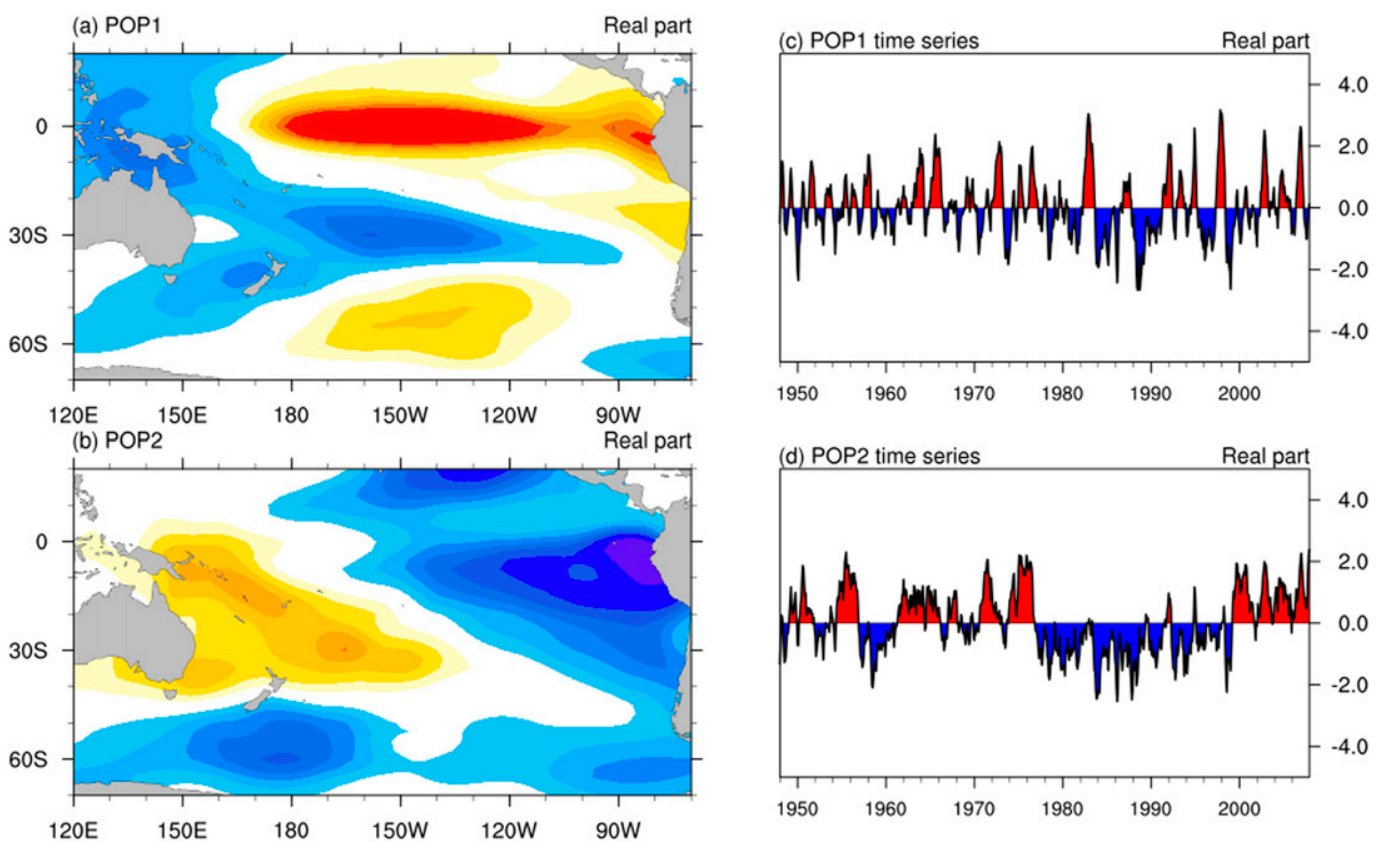

FIG. 4. The leading two least damped POP modes and POP coefficient time series in Exp1b. The contour intervals are the same for all panels but are arbitrary. Red and blue shadings indicate opposite signs.

subsurface plays an important role in reddening the surface processes in the midlatitude Pacific (e.g., Power and Colman 2006; Lou et al. 2019) and contributes to the observed SST decadal variability. With this in mind, we extended the LIM by introducing subsurface temperature variability in the form of VAT (Exp2).

In Exp2 we incorporated only TP SST thus approximating the tropical Pacific to a one-layer shallow ocean. In the midlatitude South Pacific, where subsurface processes significantly redden the corresponding surface variability and exhibit pronounced decadal variability (e.g., Fig. 10 in Lou et al. 2019), the potential predictability is well approximated by a univariate AR1 model (Fig. 11 in Lou et al. 2019). Therefore, the introduction of VAT variability in the South Pacific should further redden the surface temperature variability, generating longer time scale variations.

Figure 6 shows the leading three POP modes and the corresponding POP coefficient time series. The first POP mode (Fig. 6a) is stationary and has a considerably longer damping time scale (i.e., 101.9 months in Table 2) than any other mode. Unsurprisingly, this least damped mode also displays the greatest persistence (Fig. 6d), reflecting the most predictable subsurface signals. We can see the largest loadings of the POP1 mode is east of $180^{\circ}$ longitude where previously described topographically trapped nonlinear baroclinic Rossby waves in the vicinity of the Kermadec Ridge act to low-pass filter and enhance the decadal signature of the IPO (Lou et al. 2019).
The second propagating mode has an oscillatory period of $\sim 15$ years (Table 2 ), with a spatial pattern (Fig. 6b) resembling the SPDO. The third mode is a stationary mode with largest loadings located along the central and east equatorial Pacific (Fig. 6c), reflecting the interannual variability associated with the tropical ENSO.

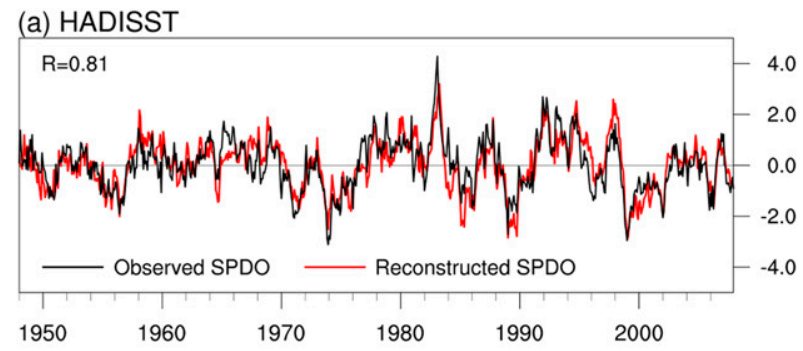

(b) ACCESS-O

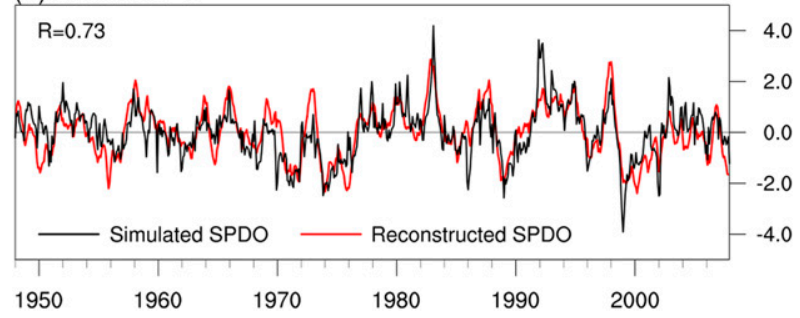

FIG. 5. The reconstructed SPDO (black) compared to the observed or simulated SPDO (red) with correlations of 0.81 and 0.73 , respectively. 

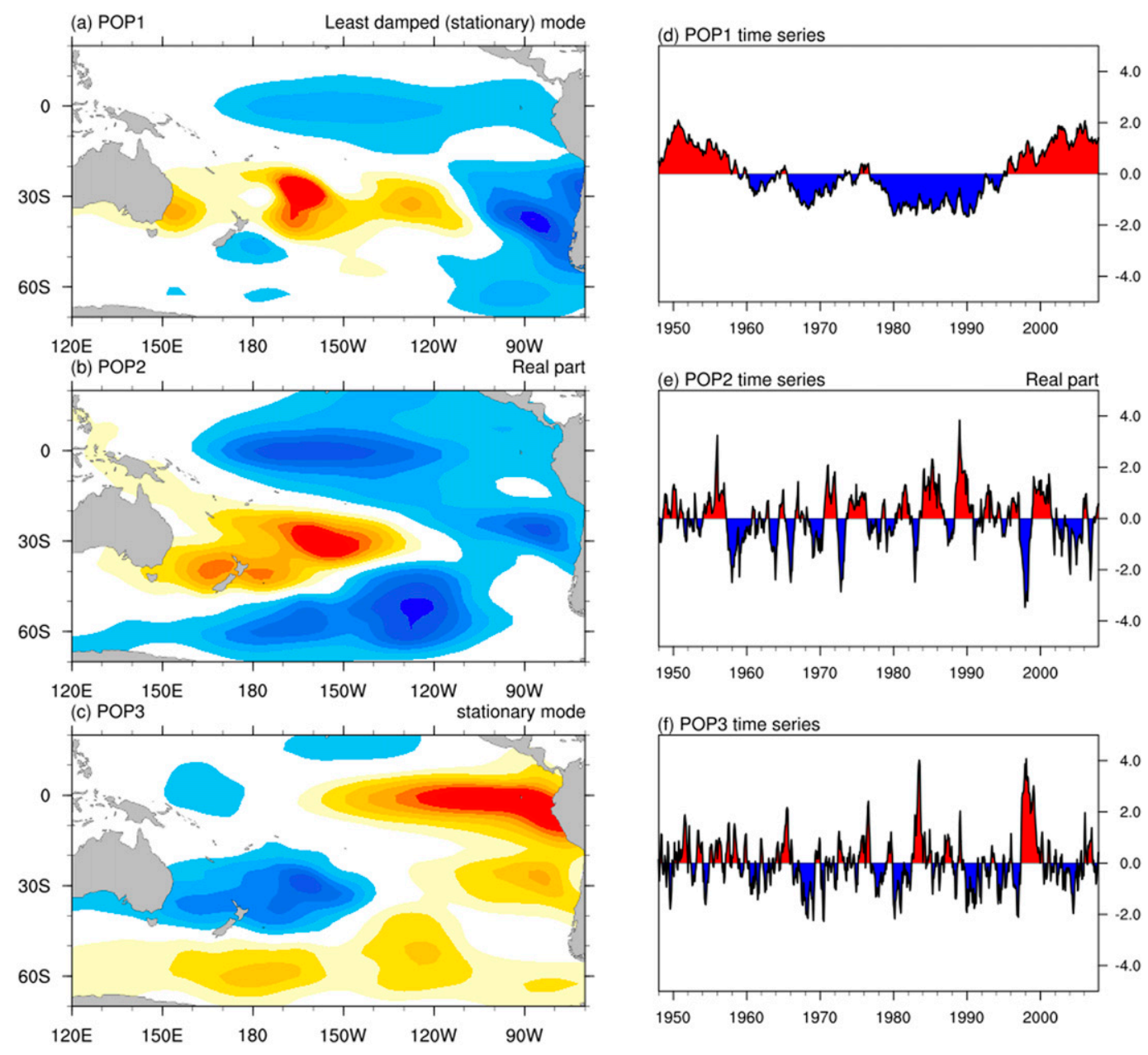

FIG. 6. The leading three least damped POP modes and corresponding POP coefficient time series in Exp2.

The above spatial patterns and temporal variability show that the overall SPDO variability arises from the combined effects of various spatiotemporal scales, including subsurface processes, local surface processes, and remote ENSO connections.

The reconstructed SPDO time series from the sum of the first three POP coefficient time series (i.e., Figs. 6d-f) is shown in Fig. 7. For comparison, the PC time series of simulated SST SPDO and VAT SPDO are also shown in Fig. 7. Although there is no single POP mode that can be identified as "the" SPDO (i.e., no individual POP coefficient time series in Fig. 6 correlates with the SPDO at a value higher than 0.42 ), the reconstructed SPDO time series is related to the SST SPDO and the VAT SPDO with correlations of 0.49 and 0.74 respectively-a clear demonstration that the subsurface variability superposes its signal onto the overall SPDO variability and reddens the surface variability. The residual SPDO component reconstructed from the POP4, 5, 6, and 7 coefficient time series (not shown) is mainly related to the high-order noise with short damping time scales.

\section{d. The most damped modes}

The damping time scales of the most damped modes in each experiment were $2.8,2.3$, and 2.4 months respectively with corresponding oscillatory periods of 4.0 , 2.2, and 2.4 years (see Table 2). Those modes with shortest damping time scales reflect the least predictable noise components in the system.

Figure 8 (left) shows the most energetic phases (i.e., real parts) of the most damped modes and Fig. 8 (right) shows the least energetic phases (i.e., imaginary parts) of the most damped modes. The spatial structures of the real and imaginary POP pairs (Fig. 8) show eastwardpropagation in the South Pacific with zonal wave-2 patterns. The spatial patterns of the real parts (Fig. 8, left) bear a strong resemblance to the second leading SST EOF of the South Pacific (shown in Figs. 1f,h) in both observations and simulation with the pattern 


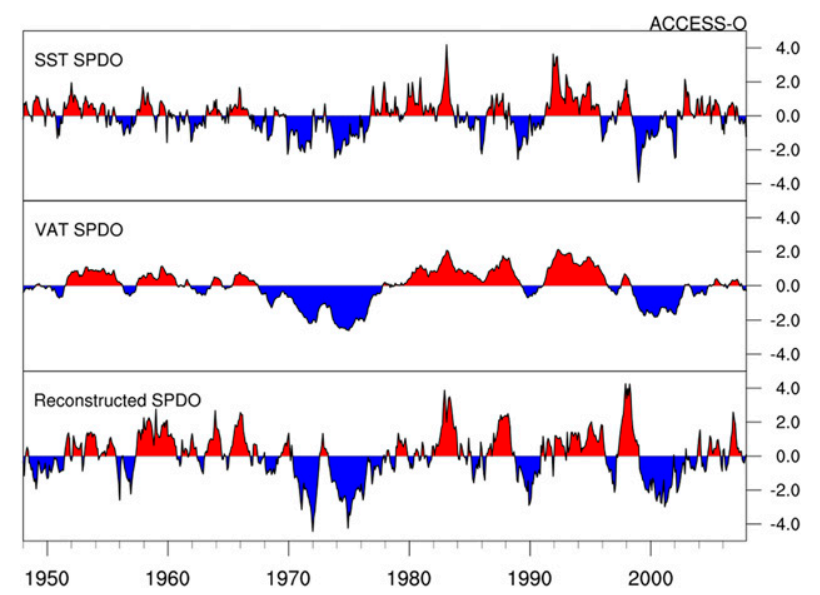

FIG. 7. PC time series of the simulated SST SPDO, VAT SPDO, and the reconstructed SPDO from the sum of the first three POP coefficient time series in Exp2.

correlations of $0.87,0.64$, and 0.67 for Exp1a, Exp1b, and Exp2 respectively. The question now arises as to whether the most damped modes are related to the second SST modes in the South Pacific.

The real parts of the POP coefficient time series associated with the most damped modes in each experiment are shown in Fig. 9. The corresponding time series in each experiment are mutually correlated ranging from 0.61 (cf. Exp1a and Exp2) to 0.81 (cf. Exp1b and Exp2). We can see that the POP coefficient time series of the most damped modes are highly variable and weakly persistent. As evident in the spatial patterns, we might expect that the POP time series of the most damped modes are also correlated to the SST PC2 in the South Pacific. We therefore calculated the temporal correlations with the observed SST SP-PC2 and found the corresponding POP coefficient time series (Fig. 9) are related to the observed SP SST-PC2 (also shown in Fig. 9) with correlations of 0.80, 0.75, and 0.67 for Exp1a, Exp1b, and Exp2 respectively.

Given that there are clear eastward-propagating wave trains in the spatial patterns of the most damped modes (Fig. 8), reminiscent of the atmospheric PSA variability (e.g., Fig. 1 in Mo 2000; Fig. 2 in O'Kane et al. 2017), it is of interest to see if the most damped noise modes might reflect the imprint of atmospheric variability onto the surface ocean. We first calculated the temporal correlations between the second SST PCs in the South Pacific and the atmospheric PSA2 time series $(r=0.31$ and 0.41 for the observations and simulation respectively, which increase to $r=0.44$ and 0.53 when the PSA2 time series is filtered with 5-month running means). However, the POP time series of the noise modes (Fig. 9) were less correlated to the 5-month filtered PSA2 time series with correlations of $0.31,0.26$, and 0.27 (all $r$ values are significant at 95\% level) for Exp1a, Exp1b, and Exp2 respectively. The low temporal correlation might be a result of using a reduced-order linear model, which does not take account of higher-order modes excluded from the linear system and other nonlinear processes. A more detailed analysis of the temporal correlation between the atmospheric PSA modes and the noise modes requires decomposing the multiscale POP and PSA time series into their constituent scales (i.e., time bands) for a chosen embedding dimension using advanced methods such as singular spectral analysis for example (see O'Kane et al. 2017) and is beyond the scope of this study.

\section{e. Predictability and forecast skill}

Given that the properties of $\mathbf{L}$ are stable, the LIM can now be used to examine predictability and forecast skill. The LIM prediction (e.g., Alexander et al. 2008) is given by

$$
\hat{\mathbf{x}}_{t+\tau}=\mathbf{G}_{\tau} \mathbf{x}_{t},
$$

where $\mathbf{G}_{\tau} \equiv \exp (\mathbf{L} \tau)$. The prediction errors of the LIM are given by

$$
\delta_{\tau}=\left\langle\left(\mathbf{x}_{t+\tau}-\mathbf{G}_{\tau} \mathbf{x}_{t}\right)^{\mathrm{T}}\left(\mathbf{x}_{t+\tau}-\mathbf{G}_{\tau} \mathbf{x}_{t}\right)\right\rangle / \operatorname{tr}[\mathbf{C}(0)],
$$

where the mean square prediction errors $\delta_{\tau}$ are normalized by the trace of the covariance matrix $\mathbf{C}(0)$.

A jackknife approach has now been applied to avoid shared information between the training and verification periods as in previous studies (e.g., Penland and Matrosova 1998; Alexander et al. 2008). In our study, we calculated $\mathbf{G}(\tau)$ using 55 years of the full-length data (60 years from 1948 to 2007), and then the excluded 5-yr periods are used to make forecasts. We used six nonoverlapping verification periods during 1976-2005 (i.e., 1916-80, 1981-85, 1986-90, etc.), when the data are most reliable. In fact, we found that using an EOF basis that excluded the verification period had an indistinguishable impact on forecast skill in our study [similar context can be found in, for example, PS95 and Newman et al. (2003)].

We then constructed a filter based on the ENMs/POPs from the tropical and South Pacific combined domain to extract the SPDO-related signals and higher-order noise components (i.e., residual; discussed in section 3b). The normalized prediction errors of the signal and residual modes with lead times of up to 24 months are shown in Fig. 10.

We note that the predictive skill of the resulting linear stochastic model of the SPDO is increased when the VAT (i.e., subsurface processes) is incorporated relative to a LIM based only on the PCs of SST (cf. Fig. 10c with Figs. 10a and 10b). In addition, using a typical meansquared prediction error of 0.5 as the reference threshold 

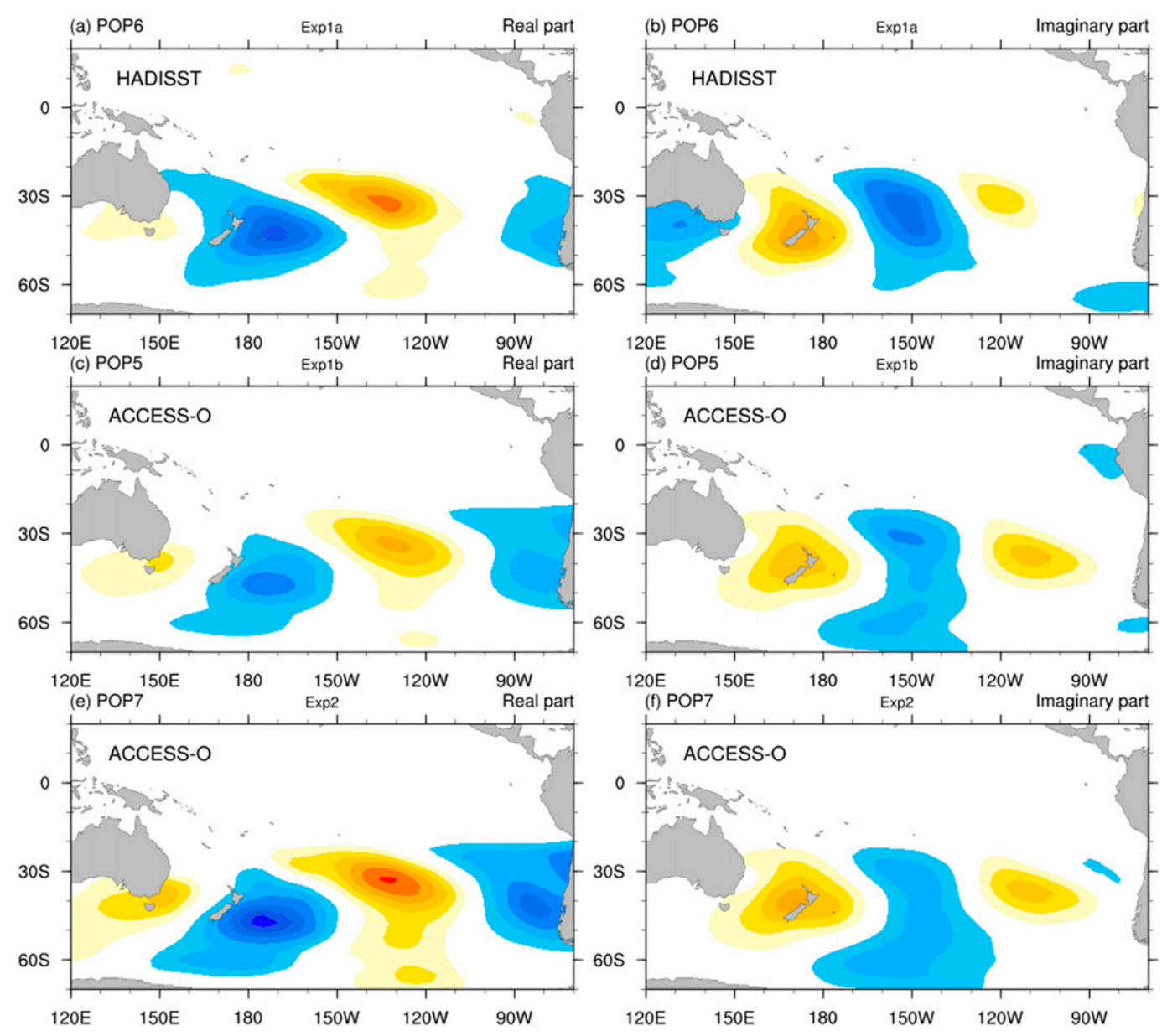

FIG. 8. The most damped modes in (top) Exp1a from the HadISST, (middle) Exp1b from the ACCESS-O, and (bottom) Exp2 from the ACCESS-O.

for a good predictive model, we see that the SPDO signal associated with ENSO and ENSO-like decadal variability is more predictable than the residual associated with the higher-order noise in all experiments.

Figure 11 shows the correlation skill between the observed/simulated SPDO and ENSO and the corresponding predicted time series for Exp1a, Exp1b, and Exp2, respectively, at leads time of 0-12 months. We can see that, by including subsurface processes in the South Pacific, the prediction skill of both the SPDO and ENSO is increased (Fig. 11). Nevertheless, replacing higher-order SST PCs with subsurface processes in the LIM does not improve the prediction skill of the SPDO for shorter leads (i.e., each experiment has very similar prediction skill for leads up to 4 months in Fig. 11a.). For longer leads ( $>4$ months), the subsurface variability starts adding more predictability to the SPDO. Meanwhile, the ENSO predictions have been improved throughout all forecast lead times from 0-12 months where subsurface processes in the South Pacific are incorporated (Fig. 11b).

The LIM forecast skill of the SPDO and ENSO is explored further in Fig. 12. Here, we show the correlations between the observed/simulated SPDO and ENSO and the corresponding predicted time series as a function of the initial months and lead times in each experiment. On the one hand, the LIM prediction skill in Figs. $12 \mathrm{a}-\mathrm{c}$ is relatively low ( $\sim 3$ months) when initiated in the boreal spring (i.e., MAM), primarily due to the boreal spring predictability barrier (Flügel and Chang 1998) when ENSO often emerges or decays. On the other hand, the ENSO prediction skill has been improved throughout all the seasons when subsurface processes in the South Pacific are included. Moreover, ENSO correlation skill is significantly higher for predictions starting after June, with skill of up to $\sim 9$ months in austral winter (i.e., JJA in Fig. 12c) when the subsurface contribution is incorporated. 


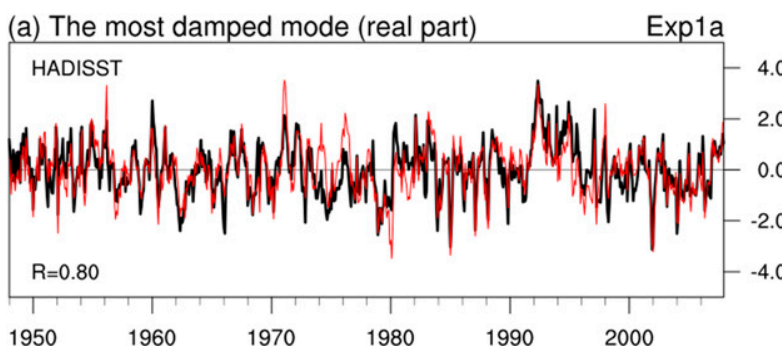

(b) The most damped mode (real part)

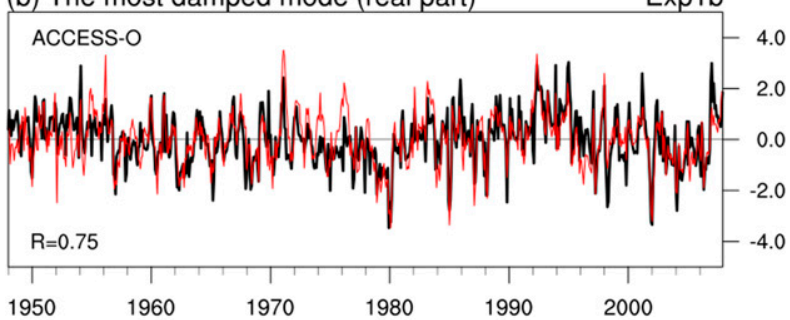

(c) The most damped mode (real part)

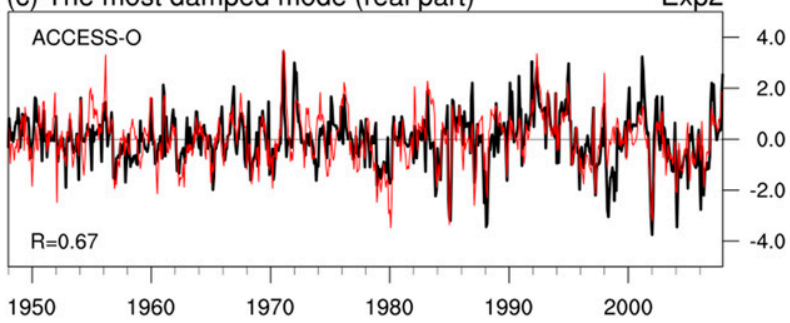

FIG. 9. The POP coefficient time series of the most damped mode (the real parts are shown by the black curves in the panels) from the Exp1a, Exp1b, and Exp2, respectively. The red curve is the observed SST PC2 in the South Pacific.

It is worth noting that the LIM predictions are comparable to state-of-the-art seasonal prediction systems (e.g., Fig. 5 in Barnston et al. 2012). In general, the SPDO has longer predictability relative to ENSO, especially when the subsurface processes are considered (Fig. 12f). However, the SPDO exhibits shorter predictability ( $\sim 3-4$ months) when the predictions are initiated in austral winter (i.e., JAS in Figs. 12d,e), which might be due to the delayed influences from tropical ENSO variability. Overall, the predictability of ENSO and the SPDO is of comparable skill. For shorter leads ( $<2$ months), ENSO in general exhibits higher correlation skill, while the SPDO exhibits longer predictability for longer leads, especially for forecasts initiated after June when including the subsurface contribution.

\section{Summary and discussion}

We have constructed reduced-order linear inverse models (LIMs) based on principal component analysis
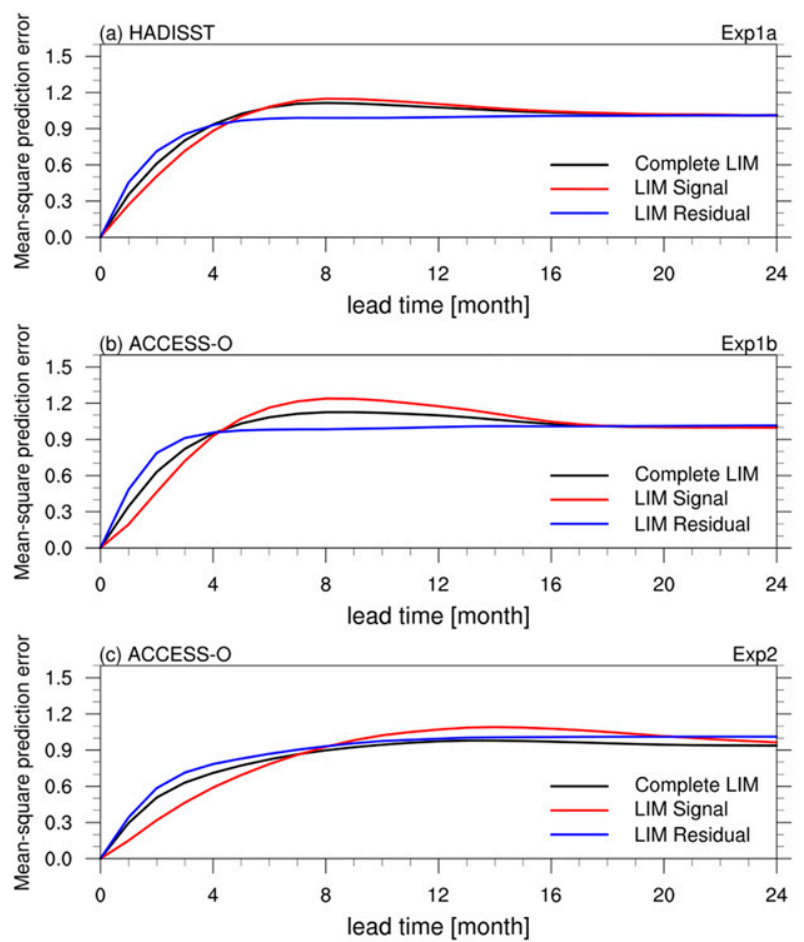

FIG. 10. Mean-square prediction errors, normalized by the trace of the covariance matrix $\mathbf{C}(0)$ for the complete LIM (considered all the eigenmodes), the LIM signal (modes $1-3$, modes 1 and 2 , and modes 1-3 in Exp1a, 1b, and 2, respectively), and the LIM residual (modes 4-6, modes 3-5, and modes 4-7 in Exp1a, 1b, and 2, respectively). Each mode index is shown in Table 2.

of detrended monthly mean tropical and South Pacific surface and subsurface temperature variability from the observations and simulations. We then demonstrated that the combined tropical and South Pacific Ocean variability can be reasonably well approximated as a stochastically driven damped linear oscillator system on interannual to (inter)decadal time scales.

The leading surface modes with damping time scales exceeding 10 months diagnosed by the LIM were by construction representative of the dynamics of a) the South Pacific Ocean and b) the interannual ENSO variability in the tropics. We demonstrated that the dynamics of the SPDO can be accurately reconstructed based on these two distinct spatiotemporal scales-one oscillating on interannual time scales associated with ENSO and one oscillating on (inter)decadal time scales with meridionally broader tropical structures relative to interannual ENSO variability. The two processes, tropical and South Pacific, combine to contribute the largest proportion of the observed SPDO variability (e.g., Fig. 5). The remaining modes, with relatively quick damping time scales, are associated with the higher-order noise components in the system and contribute to the high-frequency 
(a) SPDO

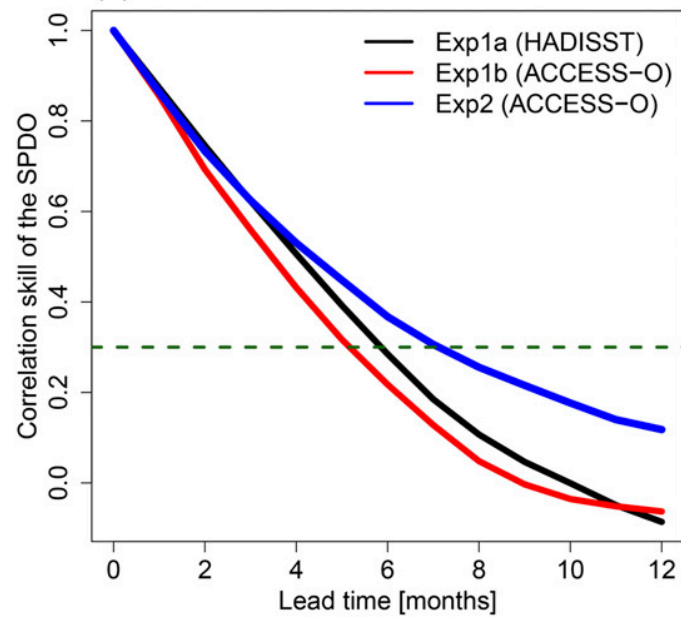

(b) ENSO

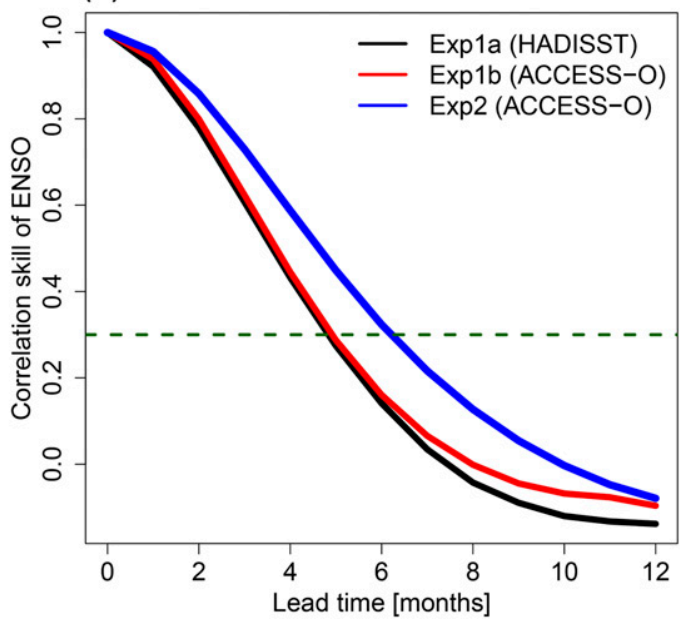

FIG. 11. The correlation skill of the (left) SPDO and (right) ENSO for Exp1a, Exp1b, and Exp2, respectively. The horizontal green line indicates the critical $r$ values for the SPDO and ENSO (at the 95\% significance level), considering the serial correlation according to Davis (1976).

fluctuations of the SPDO (Fig. 10). In all experiments, the most damped noise modes correspond to nonstationary propagating modes with damping time scales of approximately two months whose spatial patterns resemble the atmospheric synoptic PSA pattern.
The incorporation of subsurface ocean temperature variability [i.e., vertically averaged temperature (VAT) from 5- to 280-m depth] in the South Pacific into the LIM introduces long damping time scales and greater persistence. The least damped mode (Fig. 6a) displays positive loadings
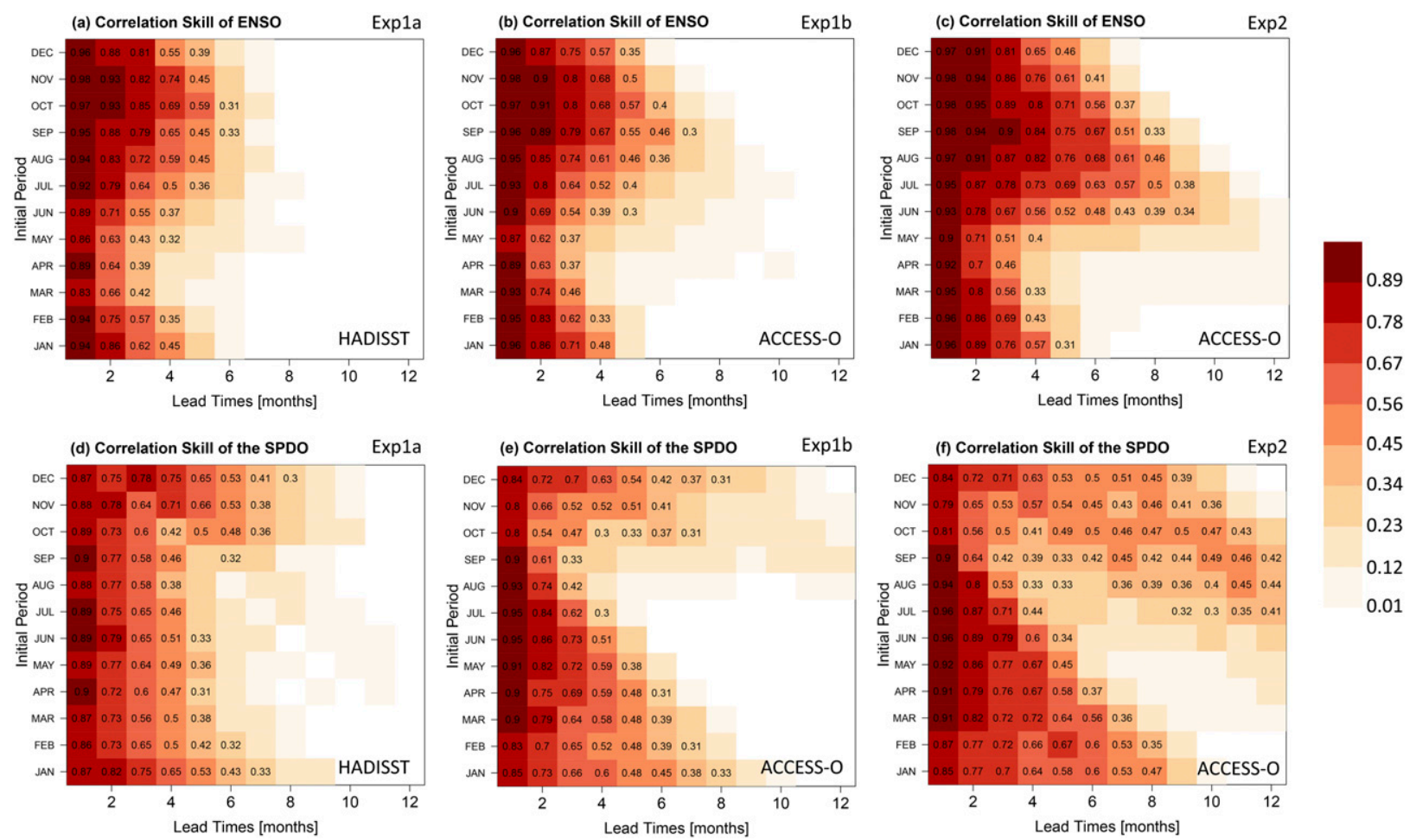

FIG. 12. The correlation skill of (top) ENSO and (bottom) the SPDO initialized in different months for the SST-only experiments in (a),(d) HadISST and (b),(e) ACCESS-O, and (c),(f) the SST+VAT experiment in ACCESS-O. The significant $r$ values (at the 95\% significance level) are labeled in each plot. Significance tests take account of serial correlation according to Davis (1976). 


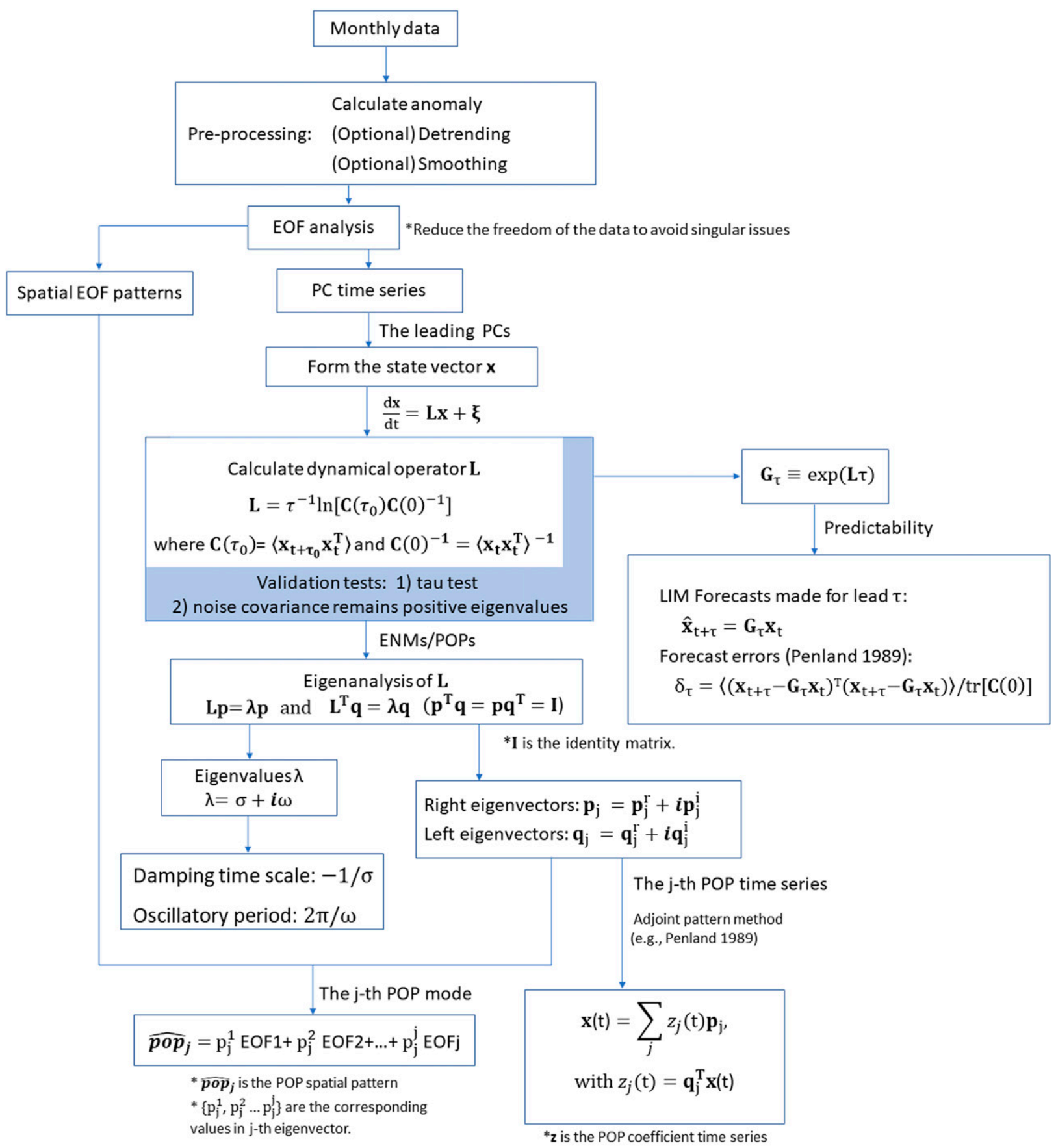

The angle brackets denote an ensemble average or an average over all $\mathrm{t}$ if the statistics of $\xi$ are stationary.

FIG. A1. Flowchart summarizing the LIM/POP analysis procedure as applied.

in the extratropical South Pacific $\left(180^{\circ}-150^{\circ} \mathrm{W}\right)$, in the vicinity of the Kermadec Ridge, consistent with ocean baroclinic Rossby wave interactions with bathymetry as discussed by Maharaj et al. (2005), O'Kane et al. (2014b), and Lou et al. (2019). With the inclusion of VAT, the reconstructed LIM SPDO exhibits enhanced decadal variability (Fig. 7), and increased predictability (Fig. 10) consistent with a reddening of the surface processes.

Last, we evaluated the forecast skill for the SPDO LIM where the low-frequency SPDO signals act as the main source of predictability relative to the high-frequency noise component (Fig. 10). Previous studies (e.g., Newman 2007; 
Alexander et al. 2008; Zanna 2012) suggest that the prediction skill and predictability based on LIMs mainly arise from the damping time scales of the corresponding eigenmodes rather than their oscillatory periods. While the presence of decadal oscillatory periods, especially at preferred time scales, suggest that skillful predictions might be possible at longer lead times, we find that those decadal periods are damped on (inter)annual and shorter time scales, thus limiting the forecast skill to seasonal time scales. Our results show that while the oscillatory periods of ENSO and the SPDO are distinct, they have very close damping time scales. Therefore, we might expect, and do indeed find, that the surface ENSO and SPDO may have very similar predictive skill. However, the inclusion of subsurface processes in the South Pacific (i.e., VAT) into the LIM, was shown to increase the predictability of the SPDO and ENSO. This indicates that the main source of extended predictability of the SPDO resides in the upper ocean arising largely due to a combination of reddening of the surface processes and internal ocean dynamics.

LIMs certainly are a useful forecast tool, and at times can provide comparable performance to fully nonlinear GCMs (e.g., Newman 2007). As such, LIMs are an additional valuable benchmark for state-of-the-art dynamical forecast systems (e.g., Newman 2013). However, since LIMs have an inherent linear decay time scale, they cannot perform ensemble forecasts and thus cannot be considered as a complete alternative to global forecast systems. Moreover, the value of ensemble forecasting systems lies in the probabilistic forecasts they provide, along with uncertainty estimates, which are distinct benefits of fully nonlinear ensemble forecasts that cannot be reproduced in LIMs.

Acknowledgments. We thank the three anonymous reviewers whose suggestions led to a substantial improvement of the paper. JL would like to thank Matthew Newman, Cecile Penland, Craig Bishop, and Laure Zanna for conversations regarding the LIM framework. $\mathrm{JL}$ is grateful for a $\mathrm{PhD}$ scholarship provided by the ARC Centre of Excellence for Climate System Science (CE110001028), University of Tasmania tuition fee scholarship, and a Quantitative Marine Science top-up scholarship [including support from the Australian Commonwealth Scientific Research Organisation (CSIRO) Postgraduate scheme]. TJO was supported by the Australian Commonwealth Scientific and Industrial Research Organisation (CSIRO) Decadal Climate Forecasting Project (https://research.csiro.au/dfp). NJH gratefully acknowledges funding support from the ARC Centre of Excellence for Climate Extremes (CE170100023). This research was undertaken with the assistance of resources from the National Computational Infrastructure (NCI), which is supported by the Australian Government.

\section{APPENDIX}

\section{Recipe of LIM/POP Method}

The method for constructing the LIM/POP is summarized in the flowchart provided in Fig. A1. Typically, linearly detrended anomalies from observations and/or simulations are used to construct the covariances prior to application of singular value decomposition. The dimensionality of the problem is reduced and an invertible (nonsingular) state vector $\mathbf{x}$ constructed by judicious choice of a set of leading principal components.

The dynamical operator $\mathbf{L}$ is then estimated from the concurrent and lagged covariance of $\mathbf{x}$ (section 2b). Before the LIM becomes useful, several validation tests (e.g., tau test and noise covariance test in section 3a) are required in order to ensure that the dynamical operator $\mathbf{L}$ is independent of the time lag $\tau_{0}$ and that the system is linear and stable.

An eigenvalue-eigenvector decomposition is then applied to the dynamical operator $\mathbf{L}$ to determine the corresponding eigenvalues and eigenvectors (e.g., section 3b). Because the dynamical operator $\mathbf{L}$ is not symmetric (Fig. 2), the eigenvalues and eigenvectors can be complex. The damping time scales and the oscillatory periods are estimated from the corresponding real and imaginary parts of the eigenvalues. By applying the adjoint pattern method (section $3 b$ ), the POP coefficient time series is estimated as the dot product of $\mathbf{x}$ with the adjoint patterns $\mathbf{q}_{j}$, which are the normalized eigenvectors of $\mathbf{L}^{\mathrm{T}}$. Projection of the corresponding eigenvectors onto the EOF spatial patterns yields the POP patterns (e.g., section 3b).

The LIM can be used for prediction for lead time $\tau$ using the linear propagator, that is,

$$
\hat{\mathbf{x}}_{t+\tau}=\mathbf{G}_{\tau} \mathbf{x}_{t},
$$

where $\hat{\mathbf{x}}_{t+\tau}$ is the "best" LIM prediction (Alexander et al. 2008) and $\mathbf{G}_{\tau}$ satisfies the Green function (Penland 1989; PS95),

$$
\mathbf{G}_{\tau} \equiv \exp (\mathbf{L} \tau)=\left\langle\mathbf{x}_{t+\tau} \mathbf{x}_{t}^{\mathrm{T}}\right\rangle\left\langle\mathbf{x}_{t} \mathbf{x}_{t}^{\mathrm{T}}\right\rangle^{-1} .
$$

The prediction skill of the LIM is measured using the normalized mean square prediction error and correlation skill.

\section{REFERENCES}

Alexander, M. A., and C. Deser, 1995: A mechanism for the recurrence of wintertime midlatitude SST anomalies. J. Phys. Oceanogr., 25, 122-137, https://doi.org/10.1175/ 1520-0485(1995)025<0122:AMFTRO > 2.0.CO;2.

—_, I. Bladé, M. Newman, J. R. Lanzante, N.-C. Lau, and J. D. Scott, 2002: The atmospheric bridge: The influence of 
ENSO teleconnections on air-sea interaction over the global oceans. J. Climate, 15, 2205-2231, https://doi.org/ 10.1175/1520-0442(2002)015<2205:TABTIO > 2.0.CO;2.

- L. Matrosova, C. Penland, J. D. Scott, and P. Chang, 2008: Forecasting Pacific SSTs: Linear inverse model predictions of the PDO. J. Climate, 21, 385-402, https://doi.org/10.1175/ 2007JCLI1849.1.

Barnston, A. G., M. K. Tippett, M. L. L'Heureux, S. Li, and D. G. DeWitt, 2012: Skill of real-time seasonal ENSO model predictions during 2002-11: Is our capability increasing? Bull. Amer. Meteor. Soc., 93, 631-651, https://doi.org/10.1175/ BAMS-D-11-00111.1.

Capotondi, A., and P. D. Sardeshmukh, 2015: Optimal precursors of different types of ENSO events. Geophys. Res. Lett., $\mathbf{4 2}$, 9952-9960, https://doi.org/10.1002/2015GL066171.

_ M. A. Alexander, C. Deser, and A. J. Miller, 2005: Low-frequency pycnocline variability in the northeast Pacific. J. Phys. Oceanogr., 35, 1403-1420, https://doi.org/10.1175/JPO2757.1.

Cavanaugh, N. R., T. Allen, A. Subramanian, B. Mapes, H. Seo, and A. J. Miller, 2015: The skill of atmospheric linear inverse models in hindcasting the Madden-Julian oscillation. Climate Dyn., 44, 897-906, https://doi.org/10.1007/s00382-014-2181-x.

Chen, X., and J. M. Wallace, 2015: ENSO-like variability: 19002013. J. Climate, 28, 9623-9641, https://doi.org/10.1175/JCLID-15-0322.1.

Davis, R. E., 1976: Predictability of sea surface temperature and sea level pressure anomalies over the North Pacific Ocean. J. Phys. Oceanogr., 6, 249-266, https://doi.org/10.1175/15200485(1976)006<0249:POSSTA $>2.0$.CO;2.

Delworth, T. L., and Coauthors, 2006: GFDL's CM2 global coupled climate models. Part I: Formulation and simulation characteristics. J. Climate, 19, 643-674, https://doi.org/10.1175/ JCLI3629.1.

Deser, C., M. A. Alexander, and M. S. Timlin, 1996: Upperocean thermal variations in the North Pacific during 19701991. J. Climate, 9, 1840-1855, https://doi.org/10.1175/ 1520-0442(1996)009<1840:UOTVIT >2.0.CO;2.

,$- \ldots$, and $—$ 2003: Understanding the persistence of sea surface temperature anomalies in midlatitudes. J. Climate, 16, 57-72, https://doi.org/10.1175/1520-0442(2003)016<0057: UTPOSS $>2.0 . \mathrm{CO} ; 2$.

Di Lorenzo, E., and M. D. Ohman, 2013: A double-integration hypothesis to explain ocean ecosystem response to climate forcing. Proc. Natl. Acad. Sci. USA, 110, 2496-2499, https:// doi.org/10.1073/pnas.1218022110.

Flügel, M., and P. Chang, 1998: Does the predictability of ENSO depend on the seasonal cycle? J. Atmos. Sci., 55, 3230-3243, https:// doi.org/10.1175/1520-0469(1998)055<3230:DTPOED>2.0.CO;2.

Folland, C. K., J. A. Renwick, M. J. Salinger, and A. B. Mullan, 2002: Relative influences of the interdecadal Pacific oscillation and ENSO on the South Pacific Convergence Zone. Geophys. Res. Lett., 29, 1643, https://doi.org/10.1029/2001GL014201.

Frankignoul, C., and K. Hasselmann, 1977: Stochastic climate models, Part II. Application to sea-surface temperature anomalies and thermocline variability. Tellus, 29, 289-305, https://doi.org/10.3402/tellusa.v29i4.11362.

Gehne, M., R. Kleeman, and K. E. Trenberth, 2014: Irregularity and decadal variation in ENSO: A simplified model based on principal oscillation patterns. Climate Dyn., 43, 3327-3350, https://doi.org/10.1007/s00382-014-2108-6.

Griffies, S. M., and Coauthors, 2009: Coordinated Ocean-Ice Reference Experiments (COREs). Ocean Modell., 26, 1-46, https://doi.org/10.1016/j.ocemod.2008.08.007.
Hasselmann, K., 1976: Stochastic climate models Part I. Theory. Tellus, 28, 473-485, https://doi.org/10.3402/tellusa.v28i6.11316.

_ 1988: PIPs and POPs: The reduction of complex dynamical systems using principal interaction and oscillation patterns. J. Geophys. Res., 93, $11015-11021$, https://doi.org/10.1029/ JD093iD09p11015.

Huddart, B., A. Subramanian, L. Zanna, and T. Palmer, 2016: Seasonal and decadal forecasts of Atlantic Sea surface temperatures using a linear inverse model. Climate Dyn., 49, 18331845, https://doi.org/10.1007/s00382-016-3375-1.

Leathers, D. J., B. Yarnal, and M. A. Palecki, 1991: The Pacific/ North American teleconnection pattern and United States climate. Part I: Regional temperature and precipitation associations. J. Climate, 4, 517-528, https://doi.org/10.1175/15200442(1991)004<0517:TPATPA > 2.0.CO;2.

Liu, Z., and E. Di Lorenzo, 2018: Mechanisms and predictability of Pacific decadal variability. Curr. Climate Change Rep., 4 , 128-144, https://doi.org/10.1007/s40641-018-0090-5.

Lou, J., N. J. Holbrook, and T. J. O'Kane, 2019: South Pacific decadal climate variability and potential predictability. J. Climate, 32, 6051-6069, https://doi.org/10.1175/JCLI-D-18-0249.1.

Lyu, K., X. Zhang, J. A. Church, J. Hu, and J.-Y. Yu, 2017: Distinguishing the quasi-decadal and multidecadal sea level and climate variations in the Pacific: Implications for the ENSO-like low-frequency variability. J. Climate, 30, 50975117, https://doi.org/10.1175/JCLI-D-17-0004.1.

Maharaj, A. M., P. Cipollini, and N. J. Holbrook, 2005: Observed variability of the South Pacific westward sea level anomaly signal in the presence of bottom topography. Geophys. Res. Lett., 32, L04611, https://doi.org/10.1029/2004GL020966.

Mantua, N. J., S. R. Hare, Y. Zhang, J. M. Wallace, and R. C. Francis, 1997: A Pacific interdecadal climate oscillation with impacts on salmon production. Bull. Amer. Meteor. Soc., 78, 1069-1080, https://doi.org/10.1175/1520-0477(1997)078<1069: APICOW $>2.0 . C O ; 2$

McPhaden, M. J., S. E. Zebiak, and M. H. Glatz, 2006: ENSO as an integrating concept in Earth science. Science, 314, 1740-1745, https://doi.org/10.1126/science.1132588.

Mo, K. C., 2000: Relationships between low-frequency variability in the Southern Hemisphere and sea surface temperature anomalies. J. Climate, 13, 3599-3610, https://doi.org/10.1175/ 1520-0442(2000)013<3599:RBLFVI >2.0.CO;2.

Newman, M., 2007: Interannual to decadal predictability of tropical and North Pacific sea surface temperatures. J. Climate, 20, 2333-2356, https://doi.org/10.1175/JCLI4165.1.

_ 2013: An empirical benchmark for decadal forecasts of global surface temperature anomalies. J. Climate, 26, 5260-5269, https://doi.org/10.1175/JCLI-D-12-00590.1.

—, G. P. Compo, and M. A. Alexander, 2003: ENSO-forced variability of the Pacific decadal oscillation. J. Climate, 16, 3853-3857, https://doi.org/10.1175/1520-0442(2003)016<3853: EVOTPD $>2.0 . \mathrm{CO} ; 2$.

and Coauthors, 2016: The Pacific decadal oscillation, revisited. J. Climate, 29, 4399-4427, https://doi.org/10.1175/ JCLI-D-15-0508.1.

O'Kane, T. J., R. J. Matear, M. A. Chamberlain, and P. R. Oke, 2014a: ENSO regimes and the late 1970's climate shift: The role of synoptic weather and South Pacific Ocean spiciness. J. Comput. Phys., 271, 19-38, https://doi.org/10.1016/j.jcp.2013.10.058.

E. C. J. Oliver, and N. J. Holbrook, 2014b: Storm tracks in the Southern Hemisphere subtropical oceans. J. Geophys. Res. Oceans, 119, 6078-6100, https://doi.org/ 10.1002/2014JC009990. 
— D. P. Monselesan, and J. S. Risbey, 2017: A multiscale reexamination of the Pacific-South American pattern. Mon. Wea. Rev., 145, 379-402, https://doi.org/10.1175/MWR-D-160291.1.

Penland, C., 1989: Random forcing and forecasting using principal oscillation pattern analysis. Mon. Wea. Rev., 117, 2165-2185, https://doi.org/10.1175/1520-0493(1989)117<2165:RFAFUP > 2.0.CO;2.

— temperatures using linear inverse modeling. J. Climate, 6, 1067-1076, https://doi.org/10.1175/1520-0442(1993)006<1067: PONSST $>2.0 . \mathrm{CO} ; 2$.

— sea surface temperature anomalies. J. Climate, 8, 1999-2024, https://doi.org/10.1175/1520-0442(1995)008<1999:TOGOTS> 2.0.CO;2.

_ , and L. Matrosova, 1998: Prediction of tropical Atlantic sea surface temperatures using linear inverse modeling. J. Climate, 11, 483-496, https://doi.org/10.1175/1520-0442(1998)011<0483: POTASS $>2.0 . \mathrm{CO} ; 2$.

—_ and 2006: Studies of El Niño and interdecadal variability in tropical sea surface temperatures using a nonnormal filter. J. Climate, 19, 5796-5815, https://doi.org/ 10.1175/JCLI3951.1.

Power, S., and R. Colman, 2006: Multi-year predictability in a coupled general circulation model. Climate Dyn., 26, 247-272, https://doi.org/10.1007/s00382-005-0055-y.

—_, T. Casey, C. Folland, A. Colman, and V. Mehta, 1999: Inter-decadal modulation of the impact of ENSO on Australia. Climate Dyn., 15, 319-324, https://doi.org/10.1007/ s003820050284.

Rayner, N. A., D. E. Parker, E. B. Horton, C. K. Folland, L. V. Alexander, D. P. Rowell, E. C. Kent, and A. Kaplan, 2003: Global analyses of sea surface temperature, sea ice, and night marine air temperature since the late nineteenth century. J. Geophys. Res., 108, 4407, https://doi.org/10.1029/ 2002JD002670.

Saurral, R. I., F. J. Doblas-Reyes, and J. García-Serrano, 2017: Observed modes of sea surface temperature variability in the
South Pacific region. Climate Dyn., 50, 1129-1143, https:/ doi.org/10.1007/s00382-017-3666-1.

Schneider, N., and B. D. Cornuelle, 2005: The forcing of the Pacific decadal oscillation. J. Climate, 18, 4355-4373, https://doi.org/ 10.1175/JCLI3527.1.

Schnur, R., G. Schmitz, N. Grieger, and H. V. Storch, 1993: Normal modes of the atmosphere as estimated by principal oscillation patterns and derived from quasigeostrophic theory. J. Atmos. Sci., 50, 2386-2400, https://doi.org/10.1175/1520-0469(1993) $050<2386$ :NMOTAA $>2.0$. CO; 2 .

Shakun, J. D., and J. Shaman, 2009: Tropical origins of North and South Pacific decadal variability. Geophys. Res. Lett., 36, L19711, https://doi.org/10.1029/2009GL040313.

Tang, B., 1995: Periods of linear development of the ENSO cycle and POP forecast experiments. J. Climate, 8, 682-691, https://doi.org/ 10.1175/1520-0442(1995)008<0682:POLDOT>2.0.CO;2.

Vimont, D. J., 2012: Analysis of the Atlantic meridional mode using linear inverse modeling: Seasonality and regional influences. J. Climate, 25, 1194-1212, https://doi.org/10.1175/JCLID-11-00012.1.

von Storch, H., and J. Xu, 1990: Principal oscillation pattern analysis of the 30- to 60-day oscillation in the tropical troposphere. Climate Dyn., 4, 175-190, https://doi.org/10.1007/BF00209520.

_ _ G. Bürger, R. Schnur, and J.-S. von Storch, 1995: Principal oscillation patterns: A review. J. Climate, 8, 377-400, https:// doi.org/10.1175/1520-0442(1995)008<0377:POPAR > 2.0.CO;2.

$\mathrm{Xu}$, J.-S., 1992: On the relationship between the stratospheric quasi-biennial oscillation and the tropospheric Southern Oscillation. J. Atmos. Sci., 49, 725-734, https://doi.org/ 10.1175/1520-0469(1992)049<0725:OTRBTS >2.0.CO;2.

Zanna, L., 2012: Forecast skill and predictability of observed Atlantic sea surface temperatures. J. Climate, 25, 5047-5056, https://doi.org/10.1175/JCLI-D-11-00539.1.

Zhang, Y., J. M. Wallace, and D. S. Battisti, 1997: ENSO-like interdecadal variability: 1900-93. J. Climate, 10, 1004-1020, https:// doi.org/10.1175/1520-0442(1997)010<1004:ELIV>2.0.CO;2.

_ S.-P. Xie, Y. Kosaka, and J.-C. Yang, 2018: Pacific decadal oscillation: Tropical Pacific forcing versus internal variability. J. Climate, 31, 8265-8279, https://doi.org/10.1175/JCLI-D-18-0164.1. 